\title{
Radiation damages and self-sputtering of high-radioactive dielectrics: spontaneous emission of submicronic dust particles
}

\author{
V.Baryakhtar, V.Gonchar, A.Zhidkov, V.Zhydkov \\ Interbranch Scientific and Technical Centre "Shelter" \\ of the National Academy of Sciences of Ukraine, \\ Chornobyl, Ukraine
}

Received March 31, 2002

The spontaneous emission of submicronic particles from a surface of highradioactive dielectrics has been under the experimental study for the first time. Formation of disordered regions due to intrinsic irradiation and electron sputtering of surface clusters processes turned out to be responsible for the phenomenon under observation.

Key words: radioactive dielectrics, aerosols, dust, nuclear fuel, radiation damages

PACS: $61.80 .-x, 28.41 . A k, 28.41 . B m, 28.41 . K w$

\section{Introduction}

Sputtering is a well-known phenomenon, which has been under investigation for the last decades in both the theoretical and experimental ways [1,2] for numerous substances. As usually, one can identify such a phenomenon as an emission of separate atoms (or clusters, containing a few of them only) when bombarding the condense matter surface by high-energy particles such as protons, $\alpha$-particles or heavy ions. The distinguishing feature from usual vaporization is that the atom emission process is not connected with their chaotic heat movement, but directly originates from atomic displacements, produced by their direct elastic interaction with quick particles falling down onto the surface, while the surface itself may be kept cold, i.e. sputtering is non-equilibrium process in principle. On the other hand, the displacement of atom from its native position into another quasi-equilibrium one means the creation of a point radiation defect, so the numerous radiation damages in the surface layer appear to be a necessary feature to be accompanied by a sputtering process.

*E-mail: zhidkov@ukrpack.net 
As an outcome of general fundamental considerations, one may expect to observe the phenomenon of self-sputtering for the surfaces belonging to the high-radioactive materials, containing a lot of radioactive nuclei in its volume, especially in a case, when such sorts of nuclei emit high-energy heavy particles, such as $\alpha$-particles or fission products (for fissile isotopes). Self-sputtering of radioactive dielectrics, however, has not been investigated either theoretically or experimentally until now despite an obvious practical interest to the problem for industrial purposes, where the radioactive substances, especially the spent nuclear fuel (uranium dioxide, as usual), undergo reprocessing.

There is another quite practical aspect of the above problem. During the wellknown heavy nuclear accident with Chornobyl NPP 4-th unit held in 1986, there were formed the so-called lava-like fuel-containing materials (LFCM) [3]. LFCM are the glass ceramic alkaline-earth silicate compositions (devitrified glasses) usually containing $5 \div 10$ mass percent of irradiated uranium nuclear fuel in their volume accompanied by high-radioactive fission products. An up-to-date review of LFCM main physical properties is presented in [4]. At present, about 1000 tons of such matter congestions accompanied both by other core debris and by the building constructions of the destroyed Chornobyl NPP 4-th unit are located in the so-called "Shelter" site, which had been quickly erected after 1986 accident as a forced measure directed primary towards prevention of radioactive substances dissemination in the environment. Surely, the "Shelter" site is not a hermetically sealed construction and one must consider that a large quantity of high-radioactive dielectrics, such as LFCM and irradiated nuclear fuel itself do have a direct air contact with the environment. In the recent years, one crucial experimental fact was discovered for sure [5] - both the LFCM and the irradiated uranium fuel surface have got a remarkable property: spontaneous dust generation ability, which means the ability of condensed matter surface, without any external impact, to generate and disseminate into the surrounding media (vacuum or gas) a high-disperse solid state phase, which in technological practice should be named as a dust (or as a smoke when there are present only the smallest solid particles). Such a phenomenon had been preliminary investigated in a workbench experiments [5], but possible physical mechanisms to be responsible for it are still unclear.

This paper is devoted to the experimental study of the structure of dust particles and represents an attempt to give basic suggestions about the nature of the phenomenon under observation.

\section{The distinguishing features of radiation damages to irradiated nuclear fuel and its silicate compositions}

\subsection{Main characteristics of the fuel under investigation}

The samples of irradiated fuel (uranium dioxide ceramic of $2 \% \mathrm{U}-235$ initial isotopic enrichment, which is standard for channel reactor) had been extracted from specially fractionated fuel element for a further experimental study. The sampling 
procedure has been carried out directly inside the "Shelter" site. The fuel was of approximately $12 \mathrm{MW} \cdot$ day $/ \mathrm{kg}$ burn-up, which corresponds to the $3 \cdot 10^{20}$ fission acts per $\mathrm{cm}^{3}$ (fis $/ \mathrm{cm}^{3}$ ) concentration value [6] and is typical of a destroyed 4-th Unit fuel. Such a fuel is a dielectric of high specific radioactivity, which originates from the activity of both the fission products and actinides (mainly $\mathrm{Pu}(238+239+240)$ and Am-241 isotopes) accumulated in a fuel as daughter products. Estimated specific activity value for such a fuel is $60 \mathrm{GBk} / \mathrm{kg}$ ( $\alpha$-emitters), $1000 \mathrm{GBk} / \mathrm{kg}$ ( $\beta$-activity) and $10 \mathrm{GBk} / \mathrm{kg}(\gamma$-ray) up to the current moment. The radiation damages responsible for a heavily irradiated fuel structure are caused by the fission fragments, which are the heavy multi-charged ions of $60 \div 160$ a.u. mass interval having the initial energy of the order of $150 \mathrm{MeV}$ for the pair of them. Stoichiometric $\mathrm{UO}_{2}$ is a substance of a high enough radiation steadiness. Hence, this kind of irradiated fuel has just got the same main mechanical properties as a fresh one. One can observe, however, the deep changes in $\mathrm{UO}_{2}$ macroscopic (in comparison with atomic dimensions) structure: the fission fragments in the end of their free path are loosing their energy mainly through the elastic atomic collisions mechanisms, which leads to the formation of the so-called displacement peaks to be the spatial regions having such an extreme concentration of stable radiation defects, that any long-range order, which is typical of crystalline solids, turned out to be destroyed in such disordered regions (DR) [7]. The dimensions of such regions typical of irradiated $\mathrm{UO}_{2}$ vary in $50 \div 100 \mathrm{~nm}$ limits depending on a fission fragment type; larger values correspond to lighter ones [7]. The noticeable overlapping of neighbouring DR can be an essential factor in case of their sufficient concentration, as it takes place in the fuel under investigation; the latter leads to the formation of clusters consisting of a few of overlapped disordered regions. Such clusters behave as complete macroscopic structural units. The possible effect of the latter will be discussed later within the framework of discussing the experimental results.

\subsection{Main radiation characteristics of silicate compositions}

The LFCM specimens were sampled directly from their locations in the "Shelter" site. Their specific radioactivity mainly corresponds to the fuel contents but there are slight deviations in isotopic proportions: due to some special features of lava formation [8], LFCM as a whole turned out to be both depleted twice or more by volatile fission products, such as Cs-137, and correspondingly enriched with some transuranium daughter products $(\mathrm{Pu}+\mathrm{Am})$ in comparison with an irradiated fuel of a similar burn-up. Thus, an up-to-date LFCM specific volume activity is about $20 \mathrm{MBk} / \mathrm{cm}^{3}$ ( $\alpha$-activity) and $300 \mathrm{MBk} / \mathrm{cm}^{3}(\beta$-emitters, mainly Sr-90). Total estimated absorbed radiation dose in LFCM volume reaches the order of 10 MGy up to the moment, which is a significant level for dielectrics, where the energy dissipation mechanisms through free electrons are negligible. LFCM radiation damages mainly originate from $\alpha$-particles, but the crucial input is connected with the accompanying heavy recoil nuclei; the heavy recoil nuclei by LFCM surface emission had been, in fact, identified in special workbench experiments [9]. Quantitative accounting of the stable radiation damages (displaced atoms) was carried out in [9], the $\beta$-particles 
effect was neglected, because such particles can produce a single (isolated) point defects only. As a result, the heavy recoil nuclei turned out to be responsible for $90 \%$ of all the atomic displacements; their total number is in $(4 \div 7) \cdot 10^{-4}$ dpa (displacements per atom) limits depending on certain fuel content. The radiation damages characteristics in LFCM are quite similar to the ones in the irradiated fuel, but there are a few distinguishing features of it. As distinguished from the fission fragments (like in fuel), all the heavy recoil nuclei to be of nearly $80 \mathrm{KeV}$ energy (coinciding with the law of conservation of momentum for $\alpha$-decay), i.e. their quasimonochromatic energy spectrum leads to the DR formation, which estimated dimension is in $25 \div 30 \mathrm{~nm}$ vicinity [10]. Such a DR up-to-date concentration in LFCM is of the order of $10^{16} \mathrm{~cm}^{-3}[9]$. Additionally, $\alpha$-particles themselves produce the same quantity of DR of a similar dimension, but DR of such a sort are not so "dense". Furthermore, such a DR concentration being sufficient for the cluster formation in LFCM volume, one can apply to this picture the same considerations as for radiation damages in fuel. Their possible clustering effect will be discussed as well.

\section{Additional experimental details}

The experimental study directed towards the self-sputtered particle structure identification had been carried out. All the main experimental procedures are described below.

The irradiated fuel and LFCM samples preparation was the first stage. The main radiation properties of the samples under investigation are in agreement with those described in the above section. The materials appointed for the investigation were cut in a special way in order to form a smooth plane face of the known area. The faces were then under polishing with a diamond compound until the surface roughness value of $0.5 \mu \mathrm{m}$ or better was achieved. Then the polished faces were thoroughly cleaned with organic solvents (mainly with absolute ethyl alcohol).

During the whole experiment, a specimen's faces were fixed in a stable horizontal position. The sputtered particles were collecting on the face oriented down the collector surface, which was located 1-2 cm under the surface, where the self-sputtering occurred. So, accumulation of the sputtered particles was provided on a collector surface from the specimens; such an exposure lasted about a fortnight as usually. The exposure procedure was realized in high vacuum conditions (0.001 $\mathrm{Pa}$ or better) in order to avoid the collector surface contamination by particles of ordinary dust always to be present in the air. The dust productivity value itself, however, as it was identified in [5], does not essentially depend on whether such a process occurs in the air atmosphere or in vacuum.

The collectors were arranged as plane plates of a typical square dimension of $1 \mathrm{~cm}^{2}$. In order to identify the possible variations of the sputtered particles' accommodation coefficient in relation to various sorts of substances, three different types of collector materials were used (metallic, semiconducting and insulating). Corresponding experimental results will be discussed later. Metallic collectors were aluminium-made, semiconducting collectors were made from a high-resistant silicon 
wafer fragment, and insulating ones were prepared by cleaving a face of a large sodium chloride single crystal. Just after the sputtering procedure, the working collector surfaces were covered with a thin (50 nm or less) layer of gold by evaporating it just in the same vacuum capacity. The latter is a traditional way for electron microscopy in order to avoid an undesirable induced electric charge accumulation. Additionally, such a gold layer prevents the possible secondary escaping of sputtered particles from the collector surface when further manipulations in the air take place.

The JSM-35C type scanning electron microscope was a basic instrument for sputtered particles structure observation at $15 \mathrm{kV}$ accelerating voltage typical regimes. The achieved spatial resolution was about $5.5 \mathrm{~nm}$ at $\times 150,000$-magnification value. A typical random error for the measured distances was $5-7 \%$, but for the smallest particles, an additional irreducible error, specified by limitations in resolution, turns out to be dominant. As far as the majority of the observed particles were of a complicated arbitrary form, following the particle plane image square determining, the equal-area circle diameter was accepted as a characteristic grade for each of them.

\section{Experimental results}

\subsection{Grade distribution of the particles}

The working surfaces of collectors, which have been prepared in the above described way, were under the electron microscopy study. The specific surface activity value for them varied in the $2-10 \mathrm{Bk} / \mathrm{cm}^{2}$ limits ( $\alpha$-activity) and $250-1500 \mathrm{Bk} / \mathrm{cm}^{2}$ ( $\beta$-activity). The corresponding relation of accommodation coefficients for metallic, semiconducting and insulating substrate materials is 3:2:6 for fuel and 2:3:25 for LFCM sputtered particles. Such values of relations coincide with the concepts, where the adhesion of high-dispersed (and electrically charged) dust to the insulating materials proved to be much stronger than to the conductive ones [11]; for the smallest particles (LFCM) the picture is more distinct. This is in agreement with the results of special experiments [5], where it was shown that decontamination procedure for insulating surfaces (preliminary contaminated by fuel or LFCM dust) is much more difficult in comparison with conductors.

The surface concentration of sputtered particles was small enough to neglect any interaction between them, which results in a quite random spatial distribution of separate particles on the collector surface. The typical picture (LFCM sputtered particles on a silicon surface) illustrating it is presented in figure 1. One can see (taking into account the scale) that the average estimated interparticle distance is of the order of $3 \mu \mathrm{m}$, while the main particle grade is less than $0.1 \mu \mathrm{m}$.

Grade distribution of the sputtered particles is a crucial point for physical interpretation and for practical applications in both. For such a purpose, a few hundreds of electron microscope images have been processed in the way described in section 3 . The grade distribution histograms for fuel and LFCM particles are shown in figure 2 and in figure 3, correspondingly. Even at a glance, one can see that the observable grade distribution is not of a form to be typical of the majority of random processes: 


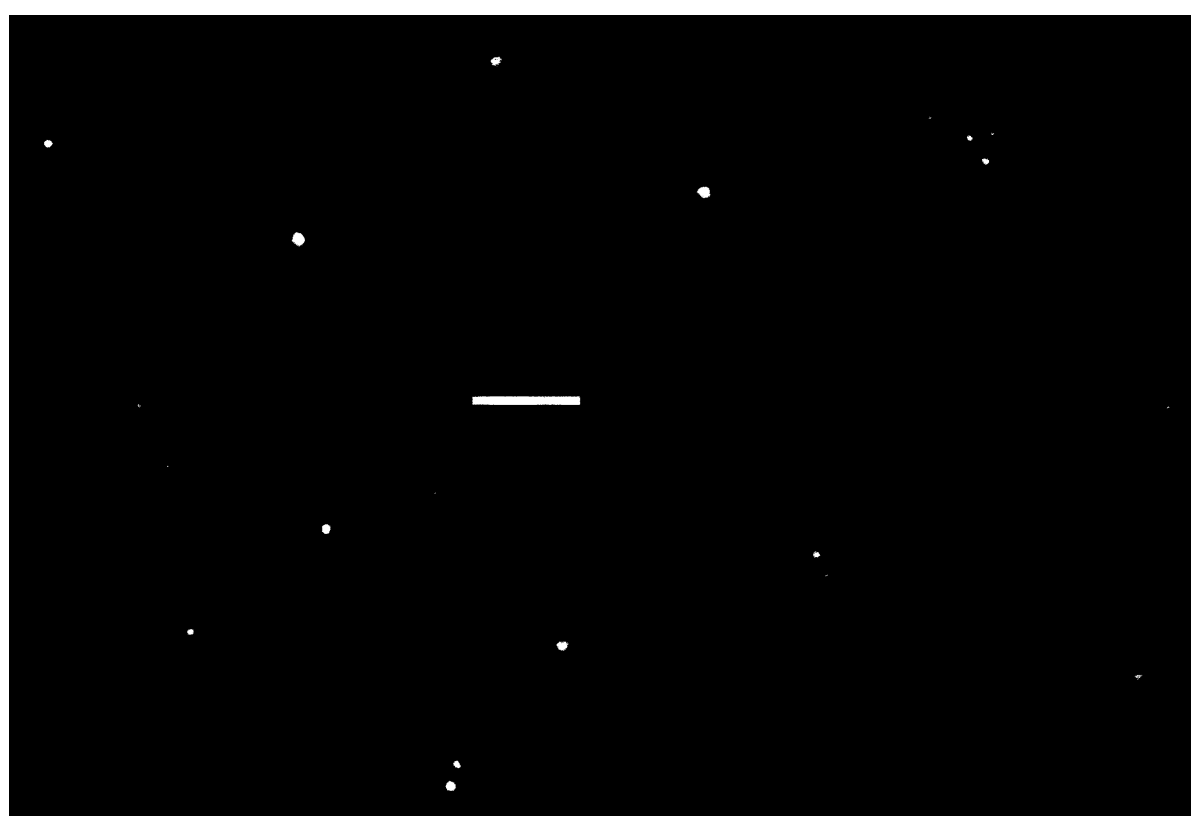

Figure 1. Typical random spatial distribution of sputtered LFCM particles, which collected on the silicon surface. White line length corresponds to $0.8 \mu \mathrm{m}$ scale.

there is a distinct lower edge in particle grade and below this threshold no particle has been observed. There are sound physical reasons for such a behaviour, which will be discussed in section 5. There is another topic for a discussion here: while in a random process the distribution should be presented as a relatively smooth dependence, each histogram has local peculiarities. In order to testify whether those distributions are robust, or the observed peculiarities are caused by insufficiency or by irreducible errors in initial experimental data, the further data processing was carried out taking into account that the distribution type is initially unknown. The histograms (figures 2,3 ) were artificially subdivided into very small steps (intervals) and then each histogram envelope was accepted as an initial distributive function $f(x)$. One can present such a function in the form of Fourier integral

$$
C(\omega)=\frac{1}{\sqrt{2 \pi}} \int_{0}^{\infty} f(x) \mathrm{e}^{-\mathrm{i} \omega x} \mathrm{~d} x,
$$

where $C(\omega)$ is $f(x)$ spectral expansion and $\omega$ is the current cycle frequency. Then, the irreducible and random error quantities in $x$ value determination (see section 3 ) were taken as a total error quantity $Q$. It is clear that $\omega>2 \pi / Q$ components in $C(\omega)$ spectrum are not of physical sense but appear to be a noise. Such a noise had been filtered by cutting off the high-frequency spectral components, and thus the processed function

$$
f_{p}(x)=\frac{1}{\sqrt{2 \pi}} \int_{-2 \pi / Q}^{+2 \pi / Q} C(\omega) \mathrm{e}^{\mathrm{i} \omega x} \mathrm{~d} \omega
$$

has been obtained as a distributive function for probability density depending on 


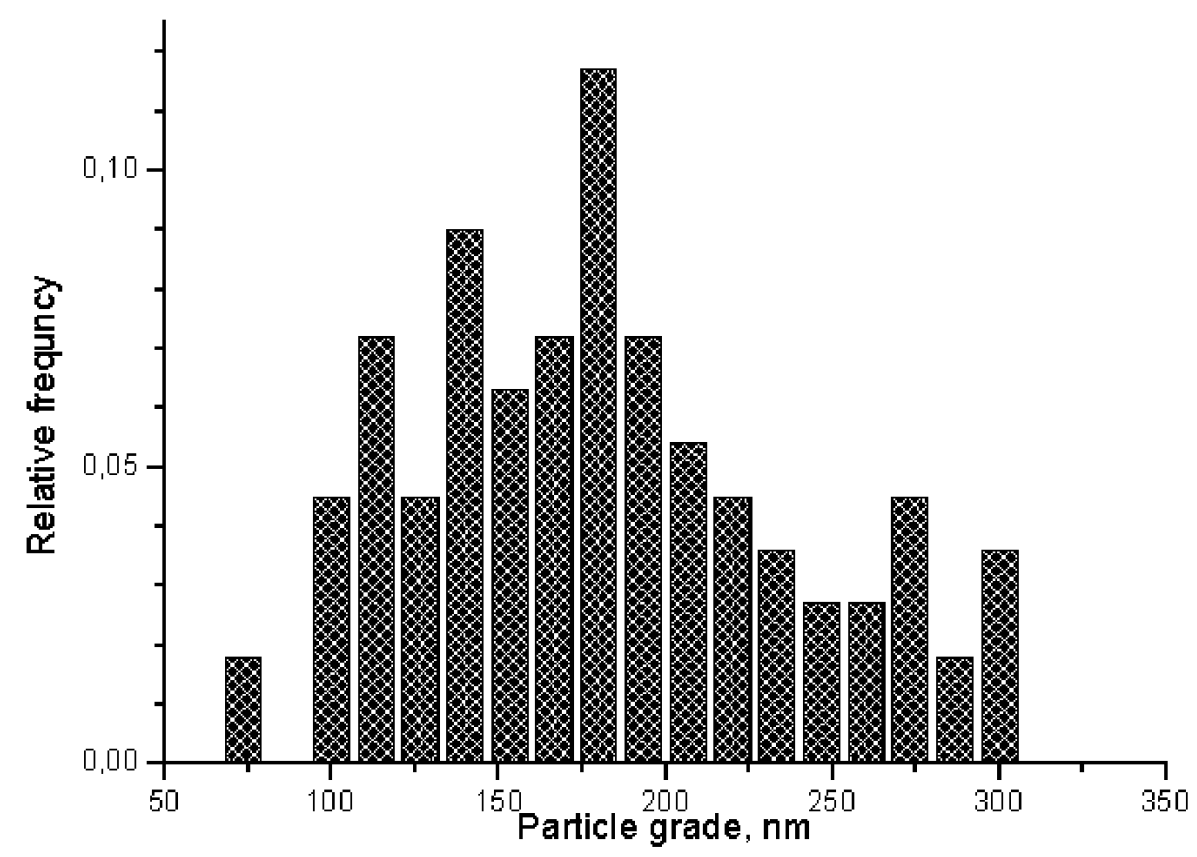

Figure 2. Normalized grade distribution histogram for sputtered fuel particles. The single observations excluded.

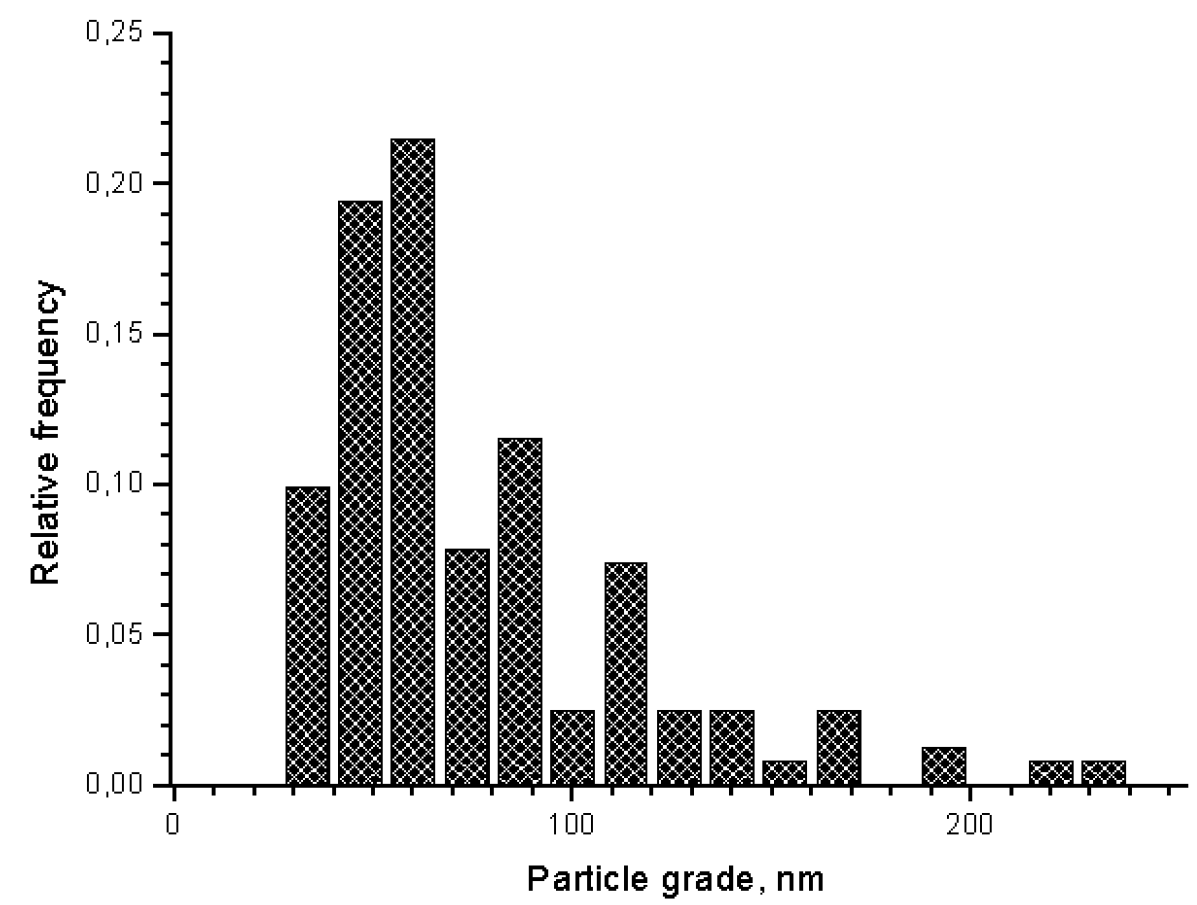

Figure 3. Normalized grade distribution histogram for sputtered LFCM particles. The single observations excluded. 


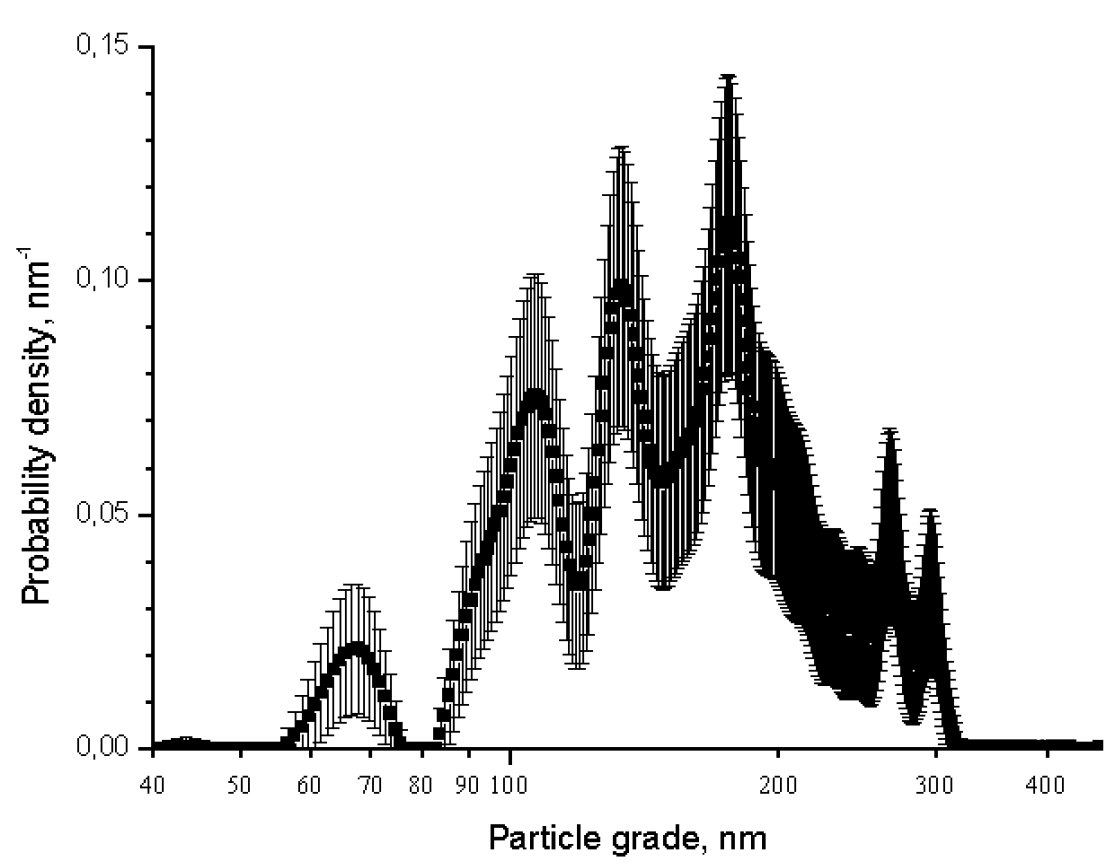

Figure 4. Normalized distributive function for fuel particles. The dashed area corresponds to the $70 \%$ level of confidence.

the grade of the particles. The above conversion, in principle, is acceptable for any smooth non-periodical function. After all, the possible error (deviations) in (2) quantity depending on $x$ value was estimated for $70 \%$ level of confidence.

The result of such a processing for fuel and LFCM is presented in figure 4 and in figure 5, correspondingly. One can see in figure 4, that distributing function argument is located in 50-400 nm limits (only the single observations were excluded), and thus such a totality emitted of the particles should be classified as submicronic fuel dust. There are some visible peculiarities in $f_{p}(x)$ behaviour, which cannot be connected with possible errors in $x$ value determining. One can judge whether each of them is distinct enough or not, when grounding on the possible statistic errors (dashed area) for the given confidence level. It is quite evident that a doubtless answer can be obtained as a result of large enough statistical processing of microscopy images only (for the given figure more than 150 of them were processed). The possible physical reasons for the observed local maxima appearance will be discussed in subsection 5.2 as well.

In figure 5, one can observe the processed distributive function for LFCM particles. Such a function has a sharp enough lower edge near the $25 \mathrm{~nm}$ value and the global maximum position of $50 \mathrm{~nm}$. There are a few doubtful additional local maxima;a possible error for $70 \%$ confidence level is indicated by a dashed area. It is clear that LFCM particles are much smaller than the fuel ones; there are physical factors responsible for it, which will be under discussion later. Such a totality of particles, in accordance with a technical classification, should be named as a high-disperse dust or as a smoke. The total number of processed microscope images for LFCM particles exceeds 250 . 


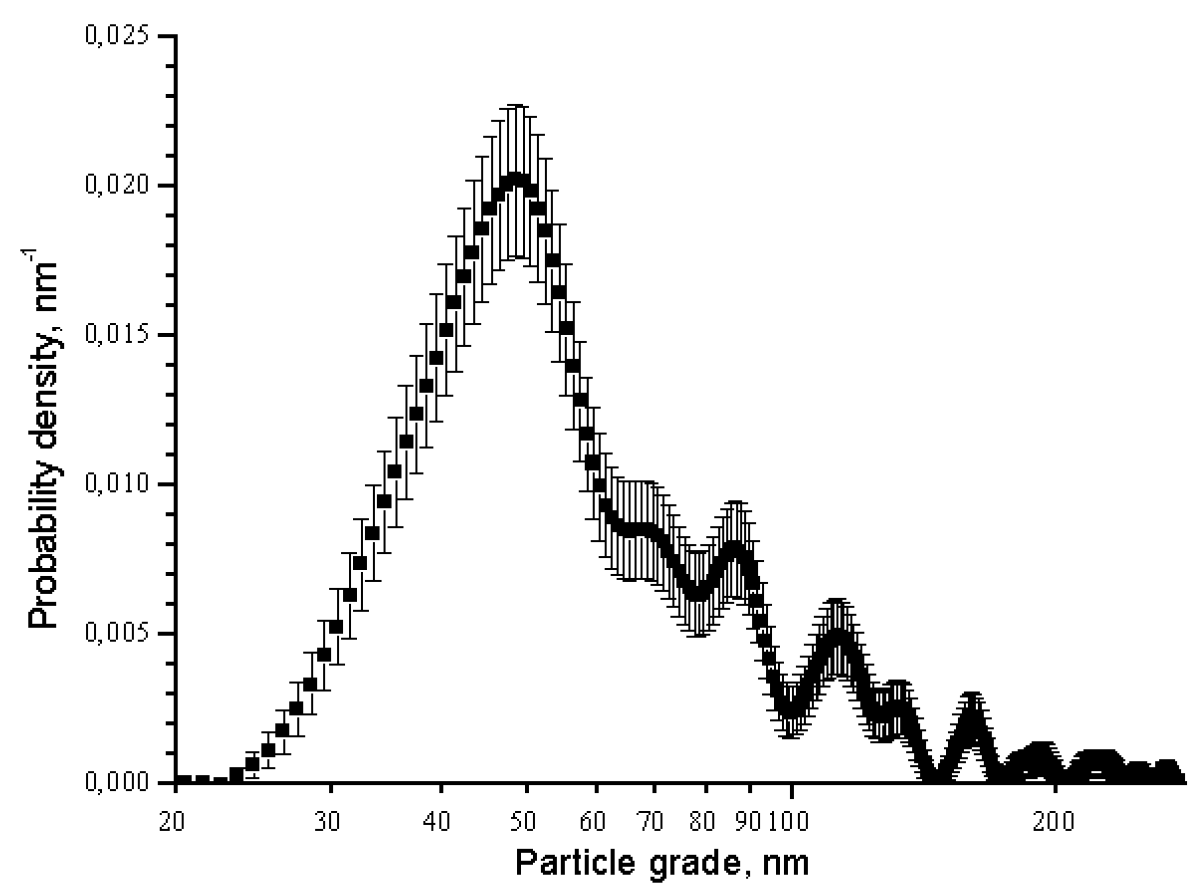

Figure 5. Normalized distributive function for LFCM particles. The dashed area corresponds to the $70 \%$ level of confidence.

\subsection{Fuel dust particle structure}

Thorough investigations show that all the fuel dust particles are of the rounded shape and the majority of them have a complicated internal structure. It turned out that the particle itself consists of a single part or of a few spherical (slightly aligned) parts which dimensions are quite similar to the DR grade in fuel (see also subsection 2.1). As usually such parts are partially the overlapped, and the overlapping degree may vary from just a slight superposition of the neighbouring DR up to the whole imposition of two DR. For example, figure 6 illustrates the fuel dust particle, which consists of two severe overlapped DR. At a glance, it looks as a single particle, but an experienced investigator can notice that the particle edges are diffused as far as the two DR imposition is not entire. Another interesting (not very typical) example is presented in figure 7. One can observe here the dust particle composed of two slightly overlapped DR. The left one corresponds to the DR of the smallest grade $(\sim 60 \mathrm{~nm})$; such kind of DR being responsible for single-DR smallest dust particles formation, which is reflected by the left peak of distributing function (see figure 4$)$. The right one corresponds to the almost largest DR ( 100 nm), which might be responsible for conforming peculiarity (near $110 \mathrm{~nm}$ ) belonging to the same distributing function (figure 4). The peculiarities under discussion can be visible, or even distinct enough due to the fact that a single DR quantity in fuel dominates under the clustered DR despite the very high DR concentration (see also subsection 2.1). The latter was confirmed by the data from computer simulations and will be discussed in detail in section 5. Finally, figure 8 demonstrates the relatively large 


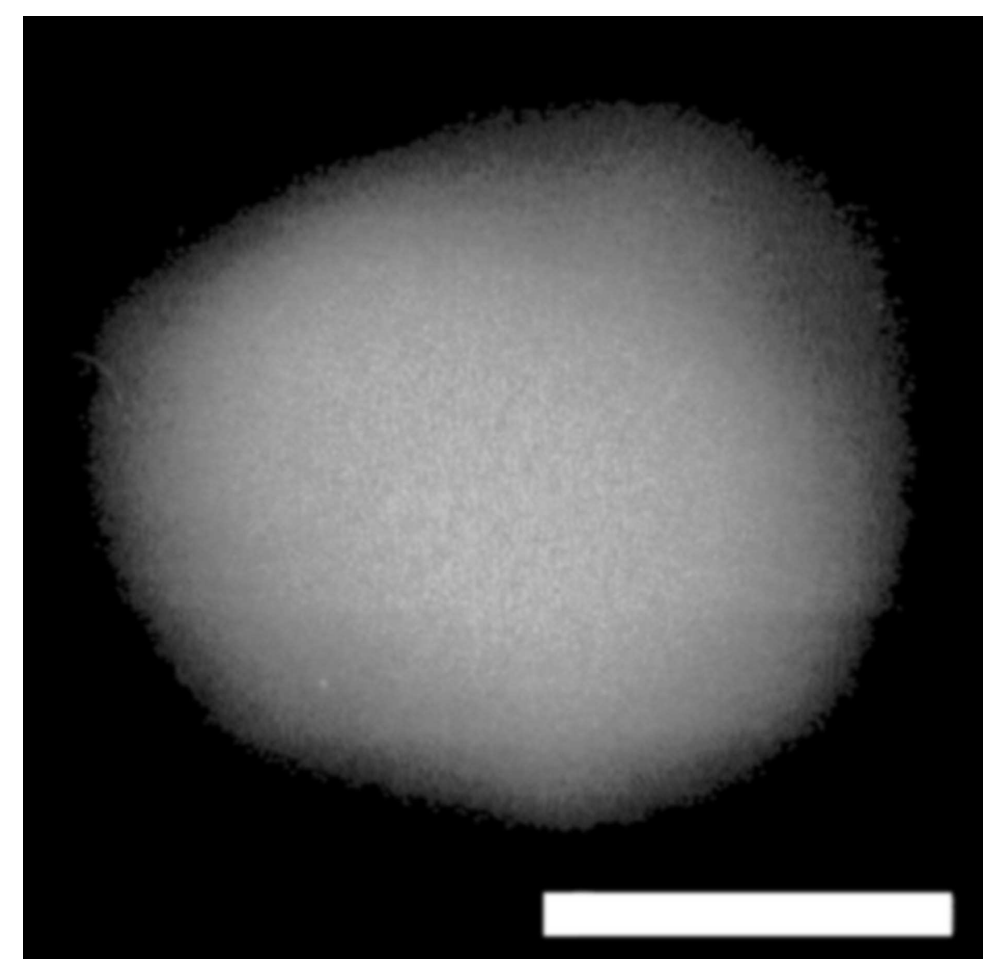

Figure 6. The fuel dust particle consisting of two severe overlapped DR. No border between them can be observed. The particle external edges are diffused. The white line length corresponds to the $80 \mathrm{~nm}$ scale.

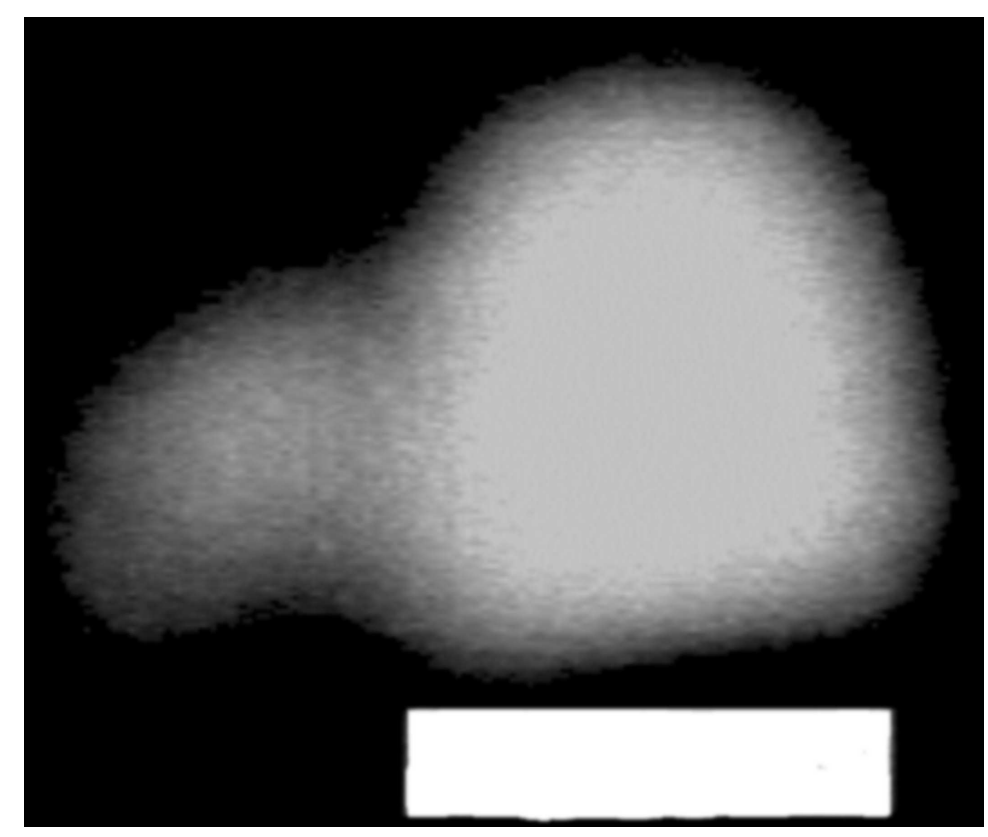

Figure 7. The fuel particle consisting of two slightly overlapped DR. One can see the inside border between them. The smaller DR dimension (left) corresponds to the smallest fuel particles grade. The white line length corresponds to the $80 \mathrm{~nm}$ scale. 


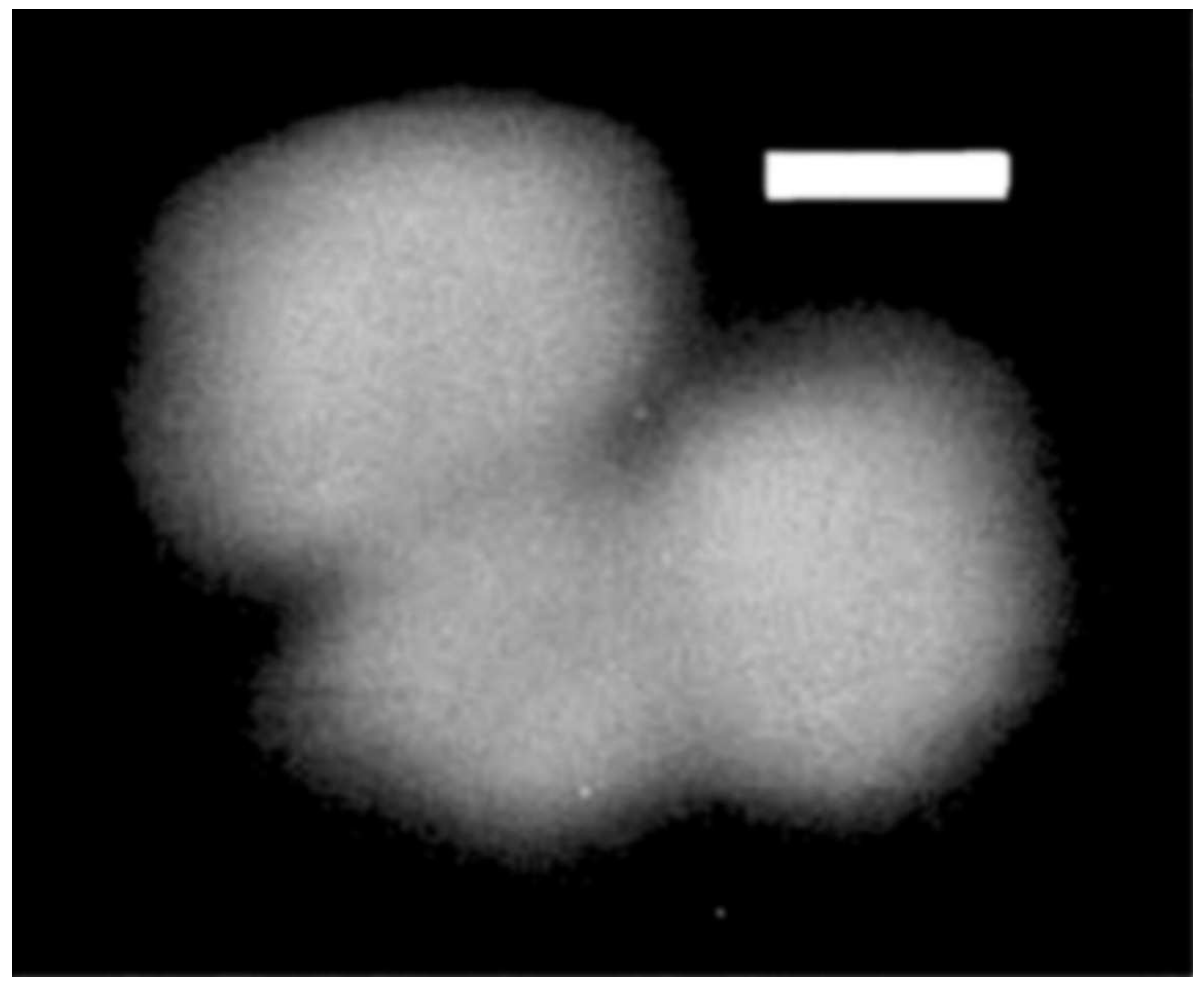

Figure 8. Relatively large fuel particle, consisting of three overlapped DR. One can observe the distinct borders between them. The white line length corresponds to the $80 \mathrm{~nm}$ scale.

fuel dust particle structure, consisting (in the figure plane projection) of three large enough and overlapped DR. Thus, one can come to a preliminary conclusion that the emitted fuel dust particles are the clusters consisting of DR, which are the main stable form of radiation damages in fuel originated from fission fragments. Numerous prolonged observations show that the formed dust particles configurations are very stable during a long period of time.

\subsection{Structure of LFCM dust particles}

The proper experimental study shows that LFCM dust particles consist of clustered DR as well. The structure of radiation damages has already been described in subsection 2.2. The smallest dust particles consist of one DR, which is illustrated in figure 9, where a few self-destructed dust particles are shown (self destruction of LFCM dust particles process will be discussed below). One can see in figure 9 (taking into account the scale) that the smallest particles (single DR) are of almost round form with a typical dimension of $30 \mathrm{~nm}$, which coincides with theoretical estimations for the mean free path of heavy recoil nuclei in LFCM $[9,10]$ (see also subsection 2.2). Just in the same figure, one can see the larger particles consisting of a few DR; such a DR may be slightly overlapped (upper right corner) or severely overlapped (the centre of the figure and the left side, where the aligned particles are visible). In general, each large dust particle does, in fact, consist of DR, which 


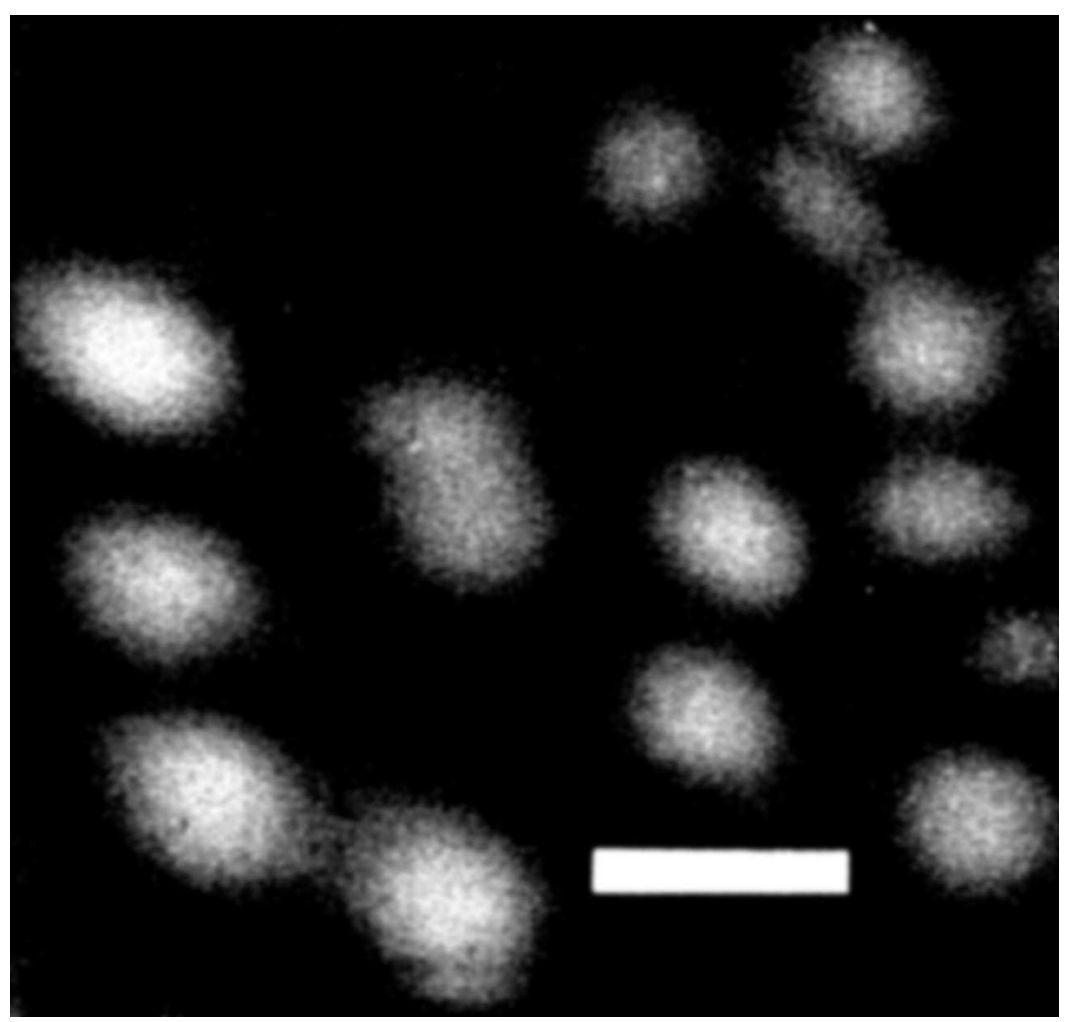

Figure 9. A few self-destructed LFCM particles. The smallest particles (single DR) are of almost round form and of $30 \mathrm{~nm}$ dimension. The larger particles consist of slightly overlapped (upper right corner) or severe overlapped DR (the left side and the centre). The white line length corresponds to the $80 \mathrm{~nm}$ scale.

can be resolved distinctly, if overlapping is not very strong. For example, figure 10 illustrates the large dust particle, where one can observe distinctly the simultaneous existence of slightly overlapped DR (lower part) and those heavily overlapped (upper part).

Thorough investigations show, that LFCM dust particles are not stable formations and their configuration is changeable with time. Sometimes one can keep track of disintegration processes, where the very large dust particle behaves like an LFCM fragment, emitting, in its turn, the smaller particles. As an example, one can see in figure 11 the large dust particle, where one DR escaped from it, forming the hole inside. The particle edges are of complicated but rounded shape, because the dust particle separation from a surface occurs along the borderline, separating the DR (or DR cluster) perimeter from the surrounding media. The largest LFCM dust particles are shown in figure 12 and one can see that their surface is spotty in accordance with DR clusters configuration; DR in LFCM, however, do not form the visible infinite DR cluster. The LFCM particles disintegration process has the following stages: the first stage occurs in the way as it is shown in figure 12, where relatively large LFCM fragments disintegrate into smaller ones having the typical dimensions $150 \div 200 \mathrm{~nm}$, which was already presented in figures 10, 11; the second stage is subdividing the smaller particles into much smaller ones consisting of a few DR only (figure 10). 


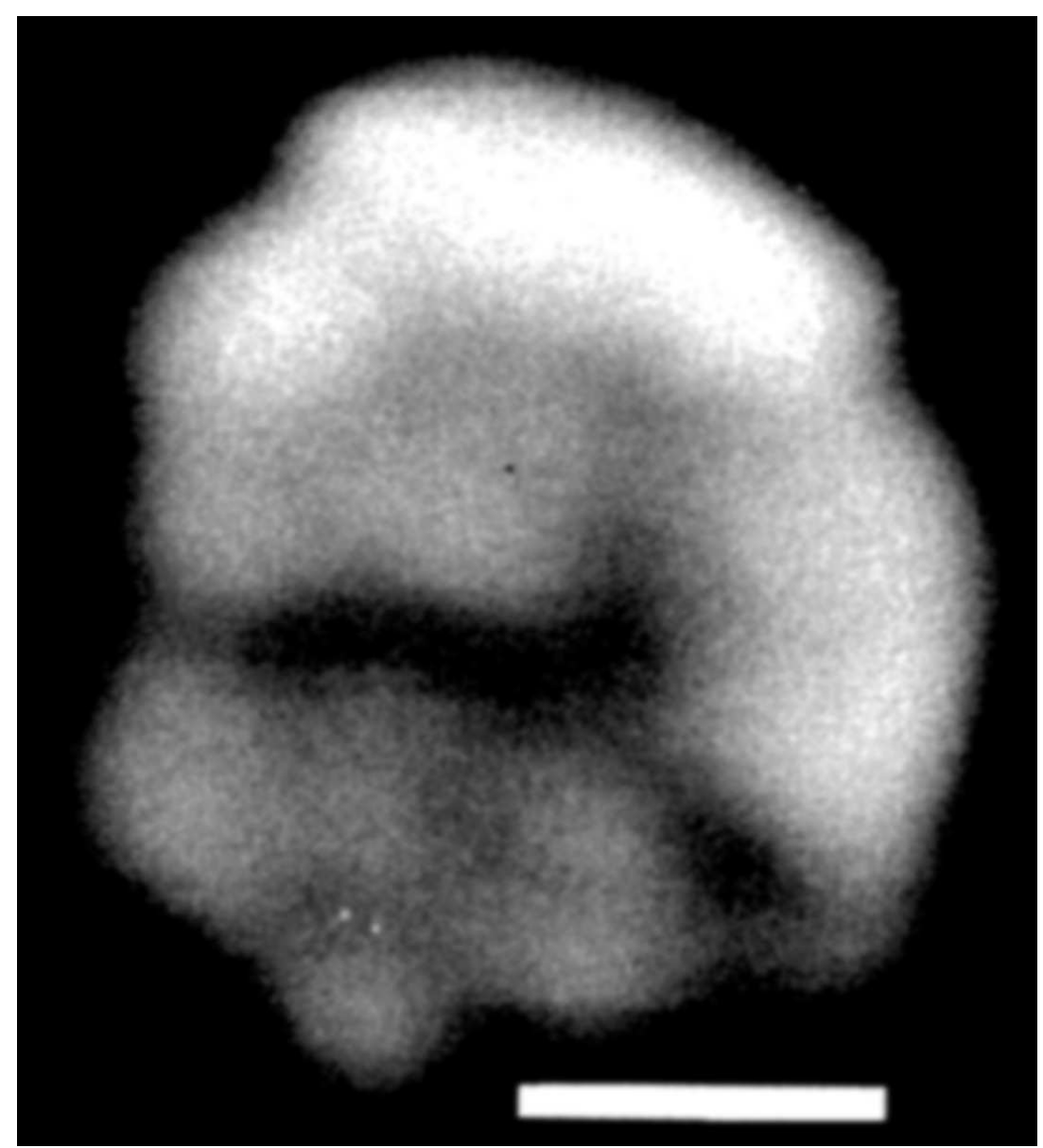

Figure 10. Large LFCM particle, where one can observe the simultaneous existence of slightly overlapped (lower part) and severe overlapped (upper part) DR. The white line length corresponds to the $80 \mathrm{~nm}$ scale.

The second stage may be almost the final one, if DR cluster itself consists of severe overlapped DR, as it is seen in the upper part of figure 10. The final stage can be realized for the particles consisting of slightly overlapped DR, where there are distinct borders between them. Such a final result is already presented in figure 9, where one can see a total disintegration. The final product is to be round particles consisting of a single DR or a little bit larger particles of an aligned form, consisting, as usually, of two severe overlapped DR.

All the above described processes lead to that measured histogram and, hence, a distributing function does not reflect exactly the real grade distribution of the emitted dust particles; the measured distribution should be shifted left (see figures 3 , 5). Such kind of an error must be taken into account as an irreducible error, because the accumulation of dust particles on a collector surface (in sufficient quantity) needs time. All the described observations had been under fulfillment during one month. For the time being, we do not see the way, how to estimate such an irreducible error quantity, but taking into consideration a few hundred pictures, the preliminary opinion is that such an error appears to be not so crucial. 


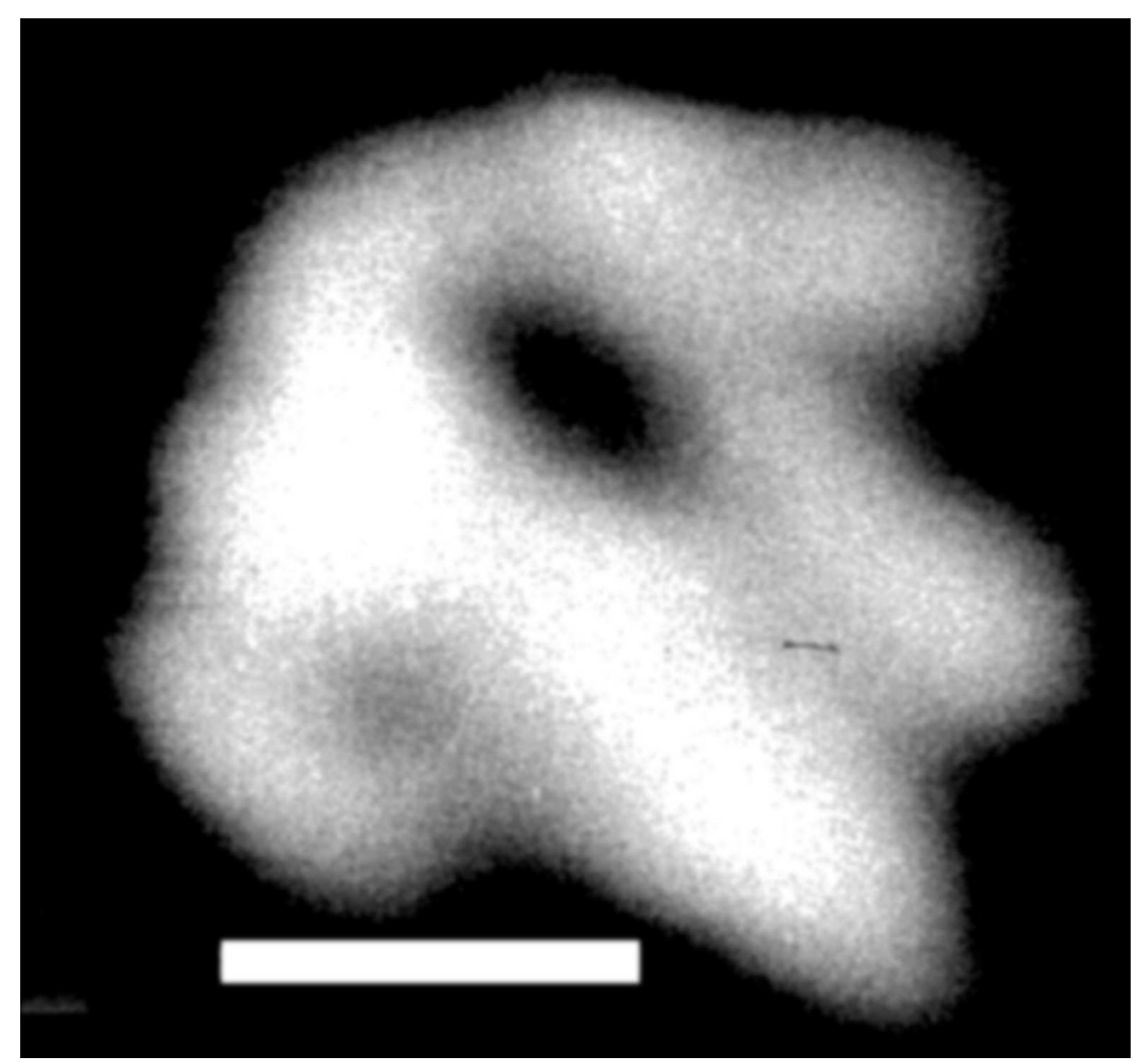

Figure 11. Large LFCM particle where one DR escaped from it. One can see the hole inside. The white line length corresponds to the $80 \mathrm{~nm}$ scale.

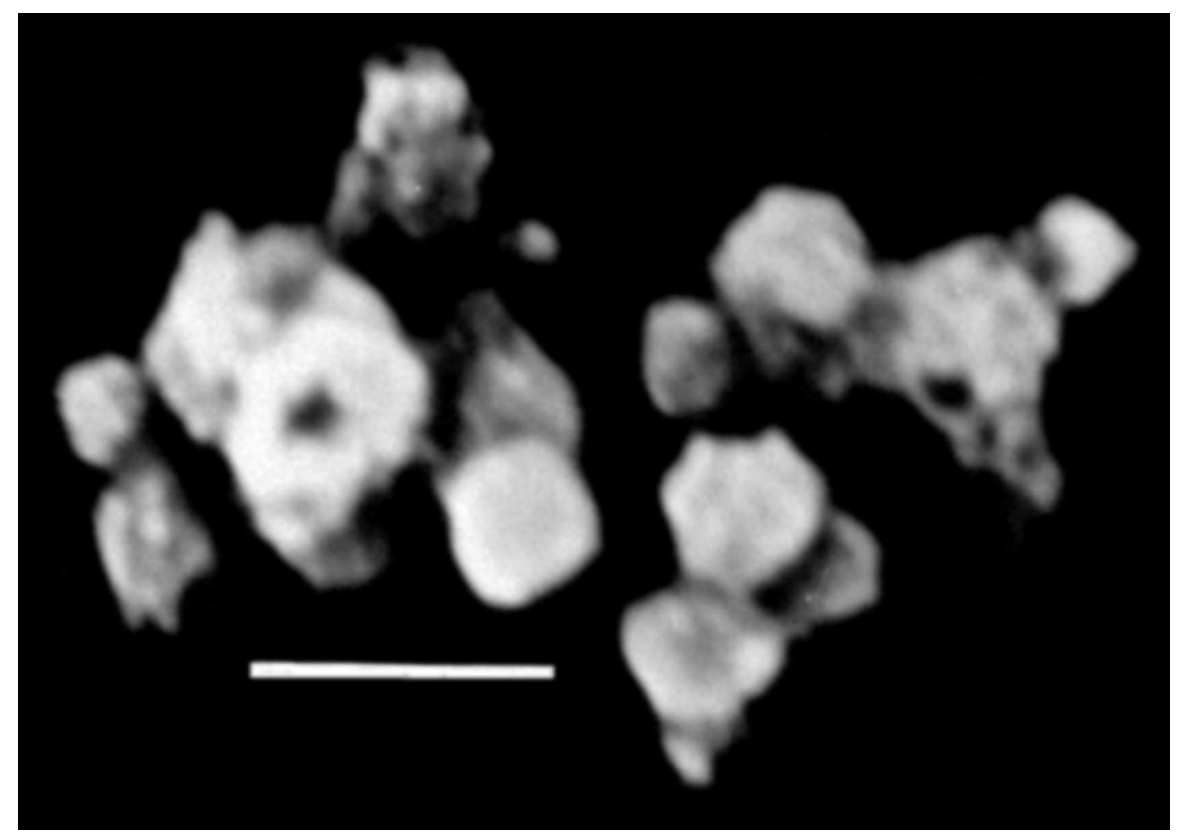

Figure 12. LFCM fragment self-disintegration into the smaller parts. The white line length corresponds to the $0.8 \mu \mathrm{m}$ scale. 


\section{Discussion}

\subsection{Preliminary estimations}

Before discussing the possible physical mechanisms that are responsible for the sputtering process, one should understand that such a process means the destruction of the surface, where the observable type of fracture is an important evidence in favour of a certain mechanism. The first feature, which can be identified unambiguously from the whole heap of dust particles observation (see figures 6-12), is that the fracture process occurs only along the boundary line subdividing the DR (DR cluster) and the surrounding condensed media. In accordance with the classification accepted in fracture mechanics [13], such kind of destruction should be classified as an intergranular fracture usually observable in materials containing the inclusions of another extraneous material. It is reasonable to suggest that DR mechanical properties differ much from those for the surrounding media, as far as inside a DR the long-range crystal order must be lost; in glasses, even the short-range order cannot be kept and DR structure in glasses is close to the abstract high-density ideal gas [14]. Thus, the DR (DR cluster) contour surface should be considered as an interphase border. The fracture mechanics claims [13], that the above classified fracture is of a brittle low-energy type, which can easy occur even under a small impact. The main source of energy for fracture processes can be the potential energy of elastic deformation originated from radiation damages. Simple preliminary estimations show that such an energy volume density is quite sufficient for total LFCM or fuel destruction. The main question under discussion, however, is the specific "trigger" mechanisms leading to its realization.

Issuing from the general considerations about possible sputtering mechanisms, one should pay attention to the direct collisions between $\alpha$-particles and surface atoms. For any material having a specific $\alpha$-activity $A$ with a mean free path for $\alpha$-particles $\Lambda$, one can calculate the particle flow intensity from the expression [9]

$$
N=\frac{A \Lambda}{4},
$$

where $N$ is the flow density. Estimating the $N$ quantities from (3), one can obtain (see initial data in subsections 2.1,2.2) $N \approx 2 \cdot 10^{5} \mathrm{~cm}^{-2} \mathrm{~s}^{-1}$ for irradiated fuel and $N \approx 10^{4} \mathrm{~cm}^{-2} \mathrm{~s}^{-1}$ for LFCM. The majority of these $\alpha$-particles, however, cannot effect directly the sputtering process as far as they escape the surface, when their energy dissipates mainly through various electron excitation mechanisms only [10]. The cross-section for elastic atomic collisions should become noticeable below a rather sharp energy threshold $E<E_{\mathrm{C}}$. Rough estimation for $E_{\mathrm{C}}$ value had been obtained in [12]:

$$
E_{\mathrm{C}} \approx 460 M \cdot \Delta E_{\mathrm{G}},
$$

where $M$ is the mass of particle in a.m.u. ( $M=4$ for $\alpha$-particles $)$ and $\Delta E_{\mathrm{G}}$ is the energy gap of dielectric media (the energy interval between mobility edges for glasses). If we accept the $\Delta E_{\mathrm{G}}$ value to be a few electron-volts (which seems to be reasonable despite the exact quantity for LFCM is unknown now), one can obtain 
from (4) the $E_{\mathrm{C}} \approx 10 \mathrm{KeV}$ value. Thus, only the fraction of an $\alpha$-particles flow, which corresponds to the $\alpha$-particles having $0<E<10 \mathrm{KeV}$ energy, can participate in elastic atom collisions which leads directly to a sputtering process. Let us calculate such a fraction intensity.

If we take the elementary area $\mathrm{d} S$, lying at a depth of $\ell$ beneath the surface, and being oriented parallel to it, one can express the elementary volume $\mathrm{d} V$ in spherical coordinates as

$$
\mathrm{d} V=r^{2} \sin \theta \mathrm{d} r \mathrm{~d} \theta \mathrm{d} \varphi
$$

where $r, \theta, \varphi$ are its coordinates, if we consider the $\mathrm{d} S$ element to be located in the centre. Then, the local flow value passing through $\mathrm{d} S$ element will be

$$
\mathrm{d} \Phi=\frac{A \cos \theta}{4 \pi r^{2}} \mathrm{~d} V \mathrm{~d} S
$$

and the corresponding integral flow density value may be expressed as

$$
\Phi=\frac{A}{4 \pi} \int_{0}^{2 \pi} \mathrm{d} \varphi \int_{0}^{\pi / 2} \mathrm{~d} \theta \int_{\Lambda-\lambda-\ell / \cos \theta}^{\Lambda} \sin \theta \cos \theta \mathrm{d} r=\frac{A}{2}(\ell+\lambda / 2) .
$$

Integration limits in (7) provide the accounting of those $\alpha$-particles only, which have $E<E_{\mathrm{C}}$ energy and are moving inside the layer of $\ell$ thickness. Here $\lambda$ is the mean free path for the particles of $E_{\mathrm{C}}$ energy. Furthermore, in accordance with [10], one can estimate $\lambda$ values as $\lambda \approx 50 \mathrm{~nm}$ for $\alpha$-particles in LFCM and $\lambda \approx 25 \mathrm{~nm}$ for those in fuel. It is not quite clear, which $l$ exactly is to be adequate for accounting, but it seems to be reasonable that the average particles grade, which corresponds to the distributive functions maximum (see also figures 4,5 ) will give satisfactory values. Taking into account the above considerations and using (7), one can find $\Phi \approx 70 \mathrm{~cm}^{2} \mathrm{~s}^{-1}$ for LFCM surface and $\Phi \approx 5000 \mathrm{~cm}^{2} \mathrm{~s}^{-1}$ for fuel.

One can also estimate the flow density $\Phi^{\prime}$ of dust particles escaping the surface, starting from the known specific volume activities $A$ and the average particles grade $d$ (one may suggest the dust particles to be of spherical form for a given rough estimation) as a relation of the emitted dust radioactivity to the radioactivity of the particle having the average grade:

$$
\Phi^{\prime}=\frac{6 \Gamma}{A \pi d^{3}}
$$

where $\Gamma$ is the dust productivity value. As far as the dust productivity level for exactly those fuel and LFCM bulk specimens had been determined previously [5], it is possible to estimate from (8), that $\Phi^{\prime} \approx 150 \mathrm{~cm}^{-2} \mathrm{~s}^{-1}$ for fuel and achieves $70,000 \mathrm{~cm}^{2} \mathrm{~s}^{-1}$ for LFCM surface.

There is one more parameter of a special interest, that is the sputtering yield $Y$ for $\alpha$-particles-induced sputtering process, i.e. $Y=\Phi^{\prime} / \Phi$ relation. From the above estimations of $(7)$ and $(8)$ one can directly obtain, that $Y \approx 0.03$ for fuel, which may be a reasonable value; the corresponding estimation for LFCM gives $Y \approx 1000$, which is a giant one. 


\subsection{Possible mechanisms responsible for the emission of $\mathrm{UO}_{2}$ particles}

While the usual sputtering product is a separate atom totality, the sputtered particles, containing $10^{6}-10^{12}$ atoms had been really identified in a few observations only. Certain results of such observations have been summarized in [1], where there was reported about a $\mathrm{UO}_{2}$ surface sputtering under high-energy protons or neutron bombardment. It was claimed that particle emission does not depend crucially on special features of external particles flow, but it depends on whether the surface has undergone a mechanical roughing or not. It means, that such a process dynamics does not depend on the details of atomic collisions, but should depend on the material structure. After the spontaneous dust emission phenomenon was identified for the first time [5], recently [15] there was detected the emission of submicronic dust particles from recrystallized $\mathrm{UO}_{2}$ fuel of a high burn-up. There was suggested in [1], that a possible physical mechanism is the (electrical) charging of surface oxide particles and the observed sputtering suppression under simultaneous external electron beam (electric charge compensation) was a serious argument in favour of such point of view. In our opinion, such a suggestion seems to be doubtful, as far as the particles emission has also been observed under the neutron flow for such conductive materials as $\mathrm{Nb}, \mathrm{V}, \mathrm{Si}[1]$. There is an additional distinguishing feature, however, for all particle emission experimental observations: such a phenomenon appears only for the surfaces having a high concentration of radiation damages in a form of displacement peaks (DR), preliminary produced by the bombardment of heavy ions.

In our case, the DR concentration reaches $5 \cdot 10^{20} \mathrm{~cm}^{-3}$ (see subsection 2.1) and simple estimations show that their totality undoubtedly forms the infinite cluster in percolation theory sense $[16,17]$ with the volume fraction belonging to the DR, (even taking into account their overlapping) turned out to be very close to $100 \%$. Thus, one may consider that $\mathrm{UO}_{2}$ of severe burn up main volume represents the whole DR with high atomic displacements density, i.e. another type of condensed matter in comparison with usual crystalline or amorphous substances. Such kind of matter, in its turn, consists of the recrystallized $\mathrm{UO}_{2}$ grains, where the grain size originates from the fission fragment mean free path at $E<E_{\mathrm{C}}$ energies and intergranular boundary configuration depending on the interaction dynamics between the neighbouring elementary DR. The important point is that both the neighbouring DR formation and their further overlapping is not an instant process, but a long process of elementary DR quantity accumulation, which occurs step by step under the external neutron flow. In this process, the "wave" forming a displacement peak (produced by a new fission fragment having the $E<E_{\mathrm{C}}$ energy in the end of its path) interacts with the spatial edge (border) of DR, which has been formed earlier. Moreover, one can notice, that such a process occurs at a high temperature, where the high mobility and diffusion coefficient for the displaced atoms under interaction are the important parameters. The authors have not found any evidence of somebody's investigation of the mentioned process in both the theoretical and experimental ways. Only one thing is clear - the intergranular boundary configuration has been changed entirely for hundred times in the described irradiated fuel during 
the elementary DR quantity accumulation. One may also suggest, that a new border in a certain place probability formation depends on the previous history and on the interaction intensity: a weaker interaction rather leads to distinct border formation, but the stronger one rather leads to a border frontolysis (one can see, for example, the figure 6 , where no border can be observed and then compare it with figures 7,8 ). In any case, the dust particle in a fuel volume (and, hence, on the surface) formation is to be the necessary preliminary stage before their emission; the latter coincides with [1]. One can still expect, that the interaction intensity, in its turn, is not a monotonous function of a distance between the DR just under the formation and the neighbouring DR, which already exists. The above peculiarities should lead to a very special behaviour of the formed dust particles grade distributive function, which is reflected in the corresponding experimental data (figure 4). The final intergranular borders configuration cannot be changeable in the irradiated fuel, as far as no additional fissions occur, when a fuel is already extracted from a reactor set-up.

The experimental data totality confirms that preliminary dust particles formation occurs not due to the roughing of the surface, as it was suggested by [1] and by some other investigators (their suggestions are summarized in [1]), but due to the heavy radiation damages, produced by fission products. The elastic deformation energy release may be a sufficient factor for the particles emission, but it is not clear now, how exactly such an energy can be concentrated in spatial regions, corresponding to the "weak bound regions". Moreover, one can point to the high electric field, which does exist on the fuel surface due to the noticeable $\beta$-particles flow escaping the surface [18]; a possible effect of this on the particle sputtering is also unclear now. The estimated sputtering efficiency value $\mathrm{Y} \approx 0.03$ is difficult for a direct comparison with other experimental results as far as any distinct result devoted to the sputtered particles quantity determination is unknown so far; such a value, however, seems to be usual in relation to the known efficiency of $\alpha$-particles in $E<E_{\mathrm{C}}$ energy region in ordinary sputtering processes.

\subsection{Possible mechanisms responsible for LFCM sputtering}

Despite the similarity of LFCM and fuel dust particle structures, the physical mechanisms responsible for particle emission have a lot of differences. First of all, the volume fraction, belonging to a DR, is far from $100 \%$ (see initial data given in subsection 2.2) and the rest LFCM volume is practically out of severe radiation damages. In order to determine such a fraction quantity, a Monte-Carlo method has been used, as far as volume diminution due to overlapping of neighbouring DR cannot be correctly estimated in analytical way. For such a purpose, the random sites problem [17] was under computation with initial parameters corresponding to the average DR grade and its volume concentration; a DR spatial distribution is supposed to be absolutely random. The results of solving the problem of random sites (the details are out of the scope of the given paper and will be the subject of a special publication) show, that the volume fraction belonging to the DR, is about $10 \%$ and there is no infinite DR cluster. The mean cluster size corresponds to its the elementary DR quantity of about 5. Regarding the above, one may con- 
sider the LFCM structure as a totality of randomly distributed in dielectric matrix (devitrified glass) isolated DR (small DR clusters). The matrix itself has only the slight point radiation defects produced mainly by intrinsic $\beta$-emitters (see also subsection 2.2) and secondary electrons accompanying $\alpha$-particles at high energies. The observed $Y \approx 1000$ value for LFCM sputtering yield, however, cannot be explained by considerations similar to those in the above section, but needs very special suggestions about the $\alpha$-particle with DR interaction mechanism details, or to involve some other sputtering mechanisms for explanation, which are not connected with $\alpha$-particles effect at all.

One should pay attention to electron sputtering phenomena, where the sharp rise of $Y$ value can be provided by electronic excitation mechanisms. Such special phenomena can be observed in good dielectrics only. The classic objects under study were alkali halides, solid Ar or Xe [19], and such oxides as $\mathrm{LiNbO}_{3}, \mathrm{LiTaO}_{3}, \mathrm{SnO}_{2}$, $\mathrm{ZnO}, \mathrm{PbO}, \mathrm{MoO}_{2}, \mathrm{SiO}_{2}$, (a good review is presented in [1]) and in some others. Furthermore, a dense electronic excitation leads to decreasing the level of energy threshold $\mathrm{E}_{d}$, corresponding to the minimum energy to be necessary for atomic displacement [1,14]. Excitons in amorphous $\mathrm{SiO}_{2}$ are always localized [14], so that such excitons often decay in non-irradiative way, especially if there are Frenkel defects in sufficient concentration; the latter, as experimental data show, can be very effective especially in amorphous $\mathrm{SiO}_{2}$. Dense electronic excitation itself, in its turn, leads to the Frenkel defect formation in LFCM matrix in the way as it was recently described for amorphous $\mathrm{SiO}_{2}$ [20]; such a process efficiency for $E^{\prime}$ centers was found to be $5 \cdot 10^{-7} \mathrm{eV}^{-1}[20]$. The estimated integral generation rate for Frenkel defects in LFCM volume originates from its radiation characteristics (see subsection 2.2) and reaches (rough estimation, where a secondary electron emission has been taken into account as well)the value of the order of $10^{8} \mathrm{~cm}^{-3} \mathrm{~s}^{-1}$; such kind of defect up-to-date concentration exceeds $10^{17} \mathrm{~cm}^{-3}$, which is a sufficient value. The above mentioned means the realization of sub-threshold mechanisms of point defect formation, which main principles were described in detail in [14] and especially in [21]. Furthermore, the numerous excited electrons construct the media, where the radiation-induced processes of defect diffusion are actual, which leads to the migration of numerous point defects to the interphase borders vicinity [22], i.e. to the border lines contouring the DR (DR clusters). Such a process, in its turn, provides the excitations decay and, hence, the energy release, namely on the mentioned borders, which can explain the character of surface destruction and the specific geometrical form of the emitted dust particles.

There is another aspect, very special for a radioactive dielectric emitting charged particles (electrons) from its surface. Really, if we proceed from the known LFCM $\beta$ activity value (subsection 2.2) and take into account that each $\alpha$-particle produces about 20 emitted secondary electrons [23], then applying the (3) relation, where $\Lambda$ in (3) will be the estimated mean free path for the electrons, one can estimate the surface electric current density $J \approx 100 \mathrm{pA} / \mathrm{cm}^{2}$. It leads to an electric charge accumulation and the electric field appearance just in a surface layer; stationary electric field strength depends on LFCM volume specific resistance and on its stat- 
ic dielectric constant. Special measurements show, that a high-electric-field LFCM three-dimensional specific resistance is of the order $10^{13} \Omega \cdot \mathrm{cm}$ and $\varepsilon \approx 8$ at a room temperature. A way to correctly estimate the electric field strength $F$ value is presented in $[23,24]$ in great detail, so the details are omitted here. Proper estimations give $F \approx 1 \mathrm{kV} / \mathrm{cm}$ only, but at local heterogeneities (such as pores, cracks and DR) vicinity, the $F$ quantity can reach very large values; one may apply here the considerations accepted in fracture mechanics [13], where the mechanical stress concentration mechanisms are under accounting in a similar way. Moreover, a DR, especially being located on the surface, has an electric conductivity, which no doubt differs from the surrounding glass matrix (due to the much higher density of localized states into the mobility gap [25]); the latter leads to the charging of DR regions at the expense of electron diffusion from the surrounding condensed media [23]. So, we have in LFCM surface the local electrically charged spatial regions, which certain localization and spatial distribution corresponds to the ones for DR (might be, this is the main factor contrasting to the DR images in electron microscopy method). The high electric charge local density, in its turn, leads to additional electronic energy losses for high-energy $\alpha$-particles (which were not under accounting in (7)) $[14,23]$ and to the additional energy release concentration in boundary line contouring DR (DR clusters). These circumstances may be a satisfactory qualitative explanation for both the certain geometrical form of the emitted dust particles and the giant $Y$ value as well.

Summarizing the above explanations, one slight but essential difference between the stable radiation defect formation and a sputtering process should be taken into account. For a sputtering process, the short-life low-energy electronic excitations are the essential factor $[1,2]$ as far as a formed particle on the surface needs a short time only to escape the surface forever, while even the single point defect formation needs the local energy release value to be beyond a certain threshold.

\section{Conclusions}

In general, there are satisfactory explanations for the main distinguishing features of the investigated phenomena. There are, however, a few difficulties and contradictions, which prevent the satisfaction to be perfect enough.

First of all, it is not clear, which parameters exactly determine the mean dust particle grade. At a first glance, at least for LFCM, it must correspond to the mean dimension of DR cluster. There was provided a special computation (details are omitted here) within the framework of random sites problem, where the quantitative relation between single, double, triple, fourfold and quintal DR clusters quantities has been determined. It turned out to be $10: 5: 2.5: 1.8: 1$ values, correspondingly, i.e. the single DR clusters quantity dominates, which is in obvious discrepancy with the observed experimental histogram and distributive function parameters (figures 3 , 5); such a discrepancy, for sure, is beyond all the possible experimental errors.

For a heavily irradiated fuel (and any dielectric having an extreme density of heavy radiation damages) the preliminary dust particle on a surface formation pro- 
cess is not clear enough, as far as one fundamental question of radiation physics of solids - in what way exactly the front of the displacements "wave" interacts with the DR edge, which does already exist (see subsection 5.2) - is out of study yet.

There is another aspect of the observed phenomena. As far as the DR concentration in LFCM will rise with time, the moment of infinite cluster in LFCM formation will come for sure, and rough estimations show that it must occur in the observable future. One thing is clear - that will lead to abrupt qualitative changes in LFCM properties; it is not clear, however, whether it will lead to the total LFCM volume conversion into the high-disperse dust, as it was partially illustrated in figures 9-12, or the dust productivity value will decay due to the partial switching off the mechanisms responsible for the local electric charge regions formation (see subsection 5.3).

At last, there is a recent circumstance, which supports a very practical interest to the phenomenon under discussion. Recently, a group of investigators $[26,27]$ provided a special detailed experimental study of aerosol composition of the air atmosphere inside the "Shelter" site. As a result, there was detected a component (fraction), corresponding to the particle grade smaller than $0.5 \mu \mathrm{m}$. Such fraction radioactive isotopes composition corresponds mainly to that in fuel (more close in LFCM), which permitted to identify it as a submicronic fuel (LFCM) dust. Quantitative data analysis indicates that such a component input in general $\alpha$-activity of "Shelter" aerosols reaches $30 \%$. If we take into account, however, the inhalation dose rate dependence on the particle grade [27], where the maximum is close to $0.1 \mu \mathrm{m}$ particles grade value, it turns out that submicronic fraction input in possible inhalation dose formation reaches $90 \%$ or more, i.e. one can suggest that the investigated phenomenon is a crucial factor, which forms the situation with radio-ecological safety for the environment. In view of this, the LFCM behaviour prognosis creation for the observable future is the most urgent practical task for today.

\section{References}

1. Behrisch R. (ed.) Sputtering by Particle Bombardment II. Top. Appl. Phys., 52, Springer, 1983.

2. Falcone G. Theory of sputtering. // La Revista del Nuovo Cimento, 1990, vol. 13, No. 1, p. 1-52.

3. Pazukhin E.M. Fuel-containing lavas of the Chornobyl NPP fourth block: topography, physico-chemical properties and formation scenario. // Radiochemistry, 1994, vol. 36, No. 2, p. $97-142$.

4. Zhidkov A.V. Fuel-containing materials of "Shelter" object today: crucial physical properties and facilities for their state prognosis creation. // Problems of Chornobyl, 2001, vol. 7, p. 23-40 (in Russian).

5. Baryakhtar V.G., Gonchar V.V., Zhidkov A.V., Klutchnikov A.A. Dust productivity of damaged irradiated fuel and lava-like fuel-containing materials of "Shelter" object. Preprint of ISTC "Shelter" of Natl. Acad. Sci. of Ukraine, No. 97-10, 1997 (in Russian). 
6. Kolobashkin V.M., Rubtsov P.M., Ruzhanskii P.A., Sidorenko V.D. Radiation Characteristics of Irradiated Nuclear Fuel. Moscow, Energoatomizdat, 1983 (in Russian).

7. Lustman B. Irradiation Effects in Uranium Dioxide. Moscow, Atomizdat, 1964 (in Russian).

8. Gonchar V.V., Zhidkov A.V. Damaged nuclear fuel with channel reactor design materials high-temperature interaction dynamics. // Problems of Chornobyl, 2002, vol. 9, p. 25-33 (in Russian).

9. Baryakhtar V.G., Gonchar V.V., Zhidkov A.V., Klutchnikov A.A. Radiation damages in lava-like fuel-containing materials of "Shelter" object. Preprint of ISTC "Shelter" of Natl. Acad. Sci. of Ukraine, No. 98-12, 1998 (in Russian).

10. Burenkov A.F., Kumakhov M.A. Spatial Distributions for Energy Released in Atomic Collision Cascades in Solids. Moscow, Energoatomizdat, 1983 (in Russian).

11. Zyman A.D. Dust and Powders Adhesion. Moscow, Khimija, 1976 (in Russian).

12. Kelly B.T. Radiation Damage to Solids. Moscow, Atomizdat, 1970 (in Russian).

13. Hellan K. Introduction to Fracture Mechanics. McGraw-Hill, 1984.

14. Silin' A.R., Trukhin A.N. Point Defects and Elementary Excitations in Crystalline and Amorphous $\mathrm{SiO}_{2}$. Riga, Zinatne, 1985 (in Russian).

15. Walker C. Radiation enhanced diffusion and gas release from recrystallised $\mathrm{UO}_{2}$ grains in high burn-up water reactor fuel. // Annual Report of Institute for Transuranium elements, Karlsruhe, JRC, EC, 2000, Report EUR 19812 BN, sect. 3.1.4, p. 86-87.

16. Kesten H. Percolation Theory for Mathematicians. Boston-Basel-Stuttgart, 1992.

17. Shklovskii B., Efros A. Electronic Properties of Doped Semiconductors. Springer, 1983.

18. Baryakhtar V., Gonchar V., Kluchnikov A., Zhidkov A. Dust productivity of fuelcontaining materials of "Shelter" object: experimental data, physical mechanisms, possible technology of prevention. // Problems of Chornobyl, 1999, vol. 5, p. 63-64.

19. Reimann C.T., Johnson R.E., Brown W.L. Sputtering and luminescence in electronically excited solid argon. // Phys. Rev. Lett., 1984, vol. 53, No. 6, p. 600-603.

20. Hosono H., Kawazoe H., Matsunami N. Experimental evidence for Frenkel defect formation in amorphous $\mathrm{SiO}_{2}$ by electronic excitation. // Phys. Rev. Lett., 1998, vol. 80, No. 2, p. 317-320.

21. Lustchik Ch.B., Vitol I.K., Elango M.A. Electronic excitations decay on radiation defects in ionic crystals. // Uspekhi Fiz. Nauk, 1977, vol. 122, No. 2, p. 223-251 (in Russian).

22. Shalaev A.M. Radiation-stimulated Processes in Metals. Moscow, Energoatomizdat, 1988 (in Russian).

23. Gromov V.V. Electric Charge in Irradiated Materials. Moscow, Energoizdat, 1982 (in Russian).

24. Gromov V.V. et al. Physico-chemical parameters of rocks, which under usage as a solid matrixes for radwaste immobilization. // Radiochemistry, 2000, vol. 42, No. 5, p. $458-461$.

25. Mott N.F., Davis E.A. Electron Processes in Non-crystalline Materials. Oxford, Clarendon Press, 1979.

26. Bondarenko O.A., Aryasov P.B., Zhydkov A.V., Medvedev S.Y., Nesmiyan I.M. Aerosol distribution on aerodynamic diameter inside the Object "Shelter": physical and dosimetric aspects. - In: Proc. of Conf. "Strahlenschutz fur Mensch und Gesselschaft im Europa von Morgen", Gmunden, Austria, 17-21 September 2001, p. 313316. 
27. Bondarenko O.A., Aryasov P.B., Melnichuk D.V., Medvedev S.Y. Analysis of aerosol distribution inside the Object "Shelter" at the Chornobyl nuclear reactor site. // Health Physics, 2001, vol. 81, No. 2, p. 114-123.

\title{
Радіаційні ушкодження та саморозпилення високорадіоактивних діелектриків: спонтанна емісія субмікронних пилових часток
}

\author{
В.Бар'яхтар, В.Гончар, О.Жидков, В.Жидков
}

Міжгалузевий науково-технічний центр "Укриття" НАН України, Чорнобиль

Отримано 31 травня 2002 р.

\begin{abstract}
Вперше експериментальним шляхом досліджено явище спонтанного вильоту субмікронних часток речовини з поверхні високорадіоактивних діелектриків. За явище, що спостерігається, відповідальні процеси формування розупорядкованих областей за рахунок внутрішнього самоопромінення та електронне розпилення поверхневих кластерів.
\end{abstract}

Ключові слова: радіоактивні діелектрики, аерозолі, пил, ядерне паливо, радіаційні ушкодження

PACS: $61.80 .-x, 28.41 . A k, 28.41 . B m, 28.41 . K w$ 
